\title{
An Analytical Evaluation of Locally Produced Iranian High School ELT Textbooks from 1970 to the Present
}

\author{
Akbar Azizifar (Corresponding author) \\ Islamic Azad University, Khorasgan branch, Isfahan, Iran \\ Tel: 98-91-8843-0411 E-mail: akb1354@yahoo.com \\ Mansoor Koosha \\ Islamic Azad University, Khorasgan branch, Isfahan, Iran \\ Tel: 98-31-1668-6818Ｅ-mail: Mansour.Koosha@yahoo.com \\ Ahmad Reza Lotfi \\ Islamic Azad University, Khorasgan branch, Isfahan, Iran \\ Tel: 98-91-3317-8603E-mail: arlotfi@yahoo.com
}

\begin{abstract}
Textbooks play a very crucial role in the process of language teaching and learning. The present study carries out an evaluation of two series of ELT textbooks used for teaching English language in Iranian high schools from 1970 to the present. For this purpose, Tucker's (1975) textbook evaluation model is employed. The results suggest that one of the main factors for the students' achievement in English language is the ELT textbooks. The researchers suggest that in the textbooks, there should be enough opportunity for the learners to practice the language they are learning communicatively.
\end{abstract}

Keywords: English language teaching, Text book design, Text book evaluation, Communicative achievement

\section{Introduction}

Textbooks are important resources for teachers in assisting students to learn every subject including English. They are the foundation of school instruction and the primary source of information for teachers. In Iran, in practice textbooks serve as the basis for much of the language input learners receive and the language practice that takes place in the classroom. For the EFL learners, the textbook becomes the major source of contact they have with the language apart from the input provided by the teacher. Hutchinson and Torres (1994) suggest that the textbook is an almost universal element of English language teaching and no teaching-learning situation, it seems, is complete until it has its relevant textbook.

According to Tomlinson (2001), textbook evaluation is an applied linguistic activity through which teachers, supervisors, administrators and materials developers can make judgments about the effect of the materials on the people using them. McGrath (2002) believes that Textbook evaluation is also of an important value for the development and administration of language learning programmes.

From 1970 two series of locally produced English language text books were used in Iranian high schools; series of Graded English books published by the Ministry of Education in 1970 and the series of Right Path to English books by Birjandi, Nowrozi, and Mahmodi in 2002.

The purpose of this study is to analyze and evaluate these two series of locally produced English language text books used in Iranian high schools from 1970 up to present time. This study provides students and teachers with a set of reference points regarding English language education material development in Iran. It is intended for teachers and students of English and people who have a general interest in English language teaching in Iran. It is intended to give a general background on some issues related to language teaching, and an overview of practical language teaching, including the teaching of the four skills.

As far as the review of literature is concerned, in Iran several projects have been carried out to evaluate textbooks, among which (Ansary \& Babaii, (2002); Yarmohammadi, (2002); and Amalsaleh, (2004)) are typical examples.

Ansary and Babaii (2002) analyzed a corpus of 10 EFL/ESL textbook reviews plus 10 EFL/ESL textbook evaluation checklists and outlined what they perceived to be the common core features of standard EFL/ESL textbooks. The major categories comprise approach, content presentation, physical make-up, and administration concerns. Each set of major features of EFL/ESL textbooks consists of a number of subcategories. They concluded the article mentioning that not all of these characteristics would be present in each and every textbook. 
Yarmohammadi (2002) evaluated the senior high school textbooks based on a revised version of Tucker's model. He came to the conclusion that these textbooks suffer from a lot of shortcomings: 1 . they are not authentic; 2 . English and Persian names are used interchangeably; and 3. oral skills are ignored. At the end, some suggestions were proposed to remedy the shortcomings.

Amalsaleh (2004) examined the representation of social factors in three types of textbooks, including junior and senior high school textbooks, based on Van Leeuwen's model (1996). According to the results, generally, the textbooks demonstrated a deferential representation of social factors that tended to portray female as performers belonging to a home context and having limited job opportunities in society. In particular, high school textbooks tended to shape normative views of gender and class relations in which a middle-class urban male was considered to be the norm.

Regarding the studies mentioned, a comprehensive study is still urgently needed to allow a subsequent assessment of the amount of use of different pronunciation points, grammatical structures, and content forms in the Iranian high school English language textbooks.

\subsection{Objectives}

Many teachers and school authorities believe that there are different factors involved in the Iranian students' achievement in English language. One of these factors may refer to the quality and characteristics of textbooks used in the process of English language teaching in the country. The present study believes that having a greater knowledge of materials development can help teachers, learners, textbook developers and the educational authorities to find new ways for improving the quality of textbooks and consequently the quality of teaching and learning English in the country's educational system.

The results of the study is hoped to benefit English language teachers, learners, and textbook developers to improve their teaching, learning, and designing of the textbooks.

As such, the study seeks answers to the following questions:

RQ1. How are the pronunciation points, content, and grammar dealt with in "Graded English" (henceforth: GE) series?

RQ2. How are the pronunciation points, content, and grammar dealt with in "Right Path to English" (henceforth: RPE) series?

\section{Method}

\subsection{Materials}

The materials of this study are the two locally produced series of English language textbooks used in Iranian high schools since1970. In order to be more specific based on simple random sampling procedure the researchers select and focus on Book Two of each of these series.

a. Book Two from the series of $G E$ books published by the Ministry of Education in 1984, and

b. Book Two from the series of RPE books by Birjandi, Nowrozi, and Mahmodi in 2002.

\subsection{Instrument}

To conduct the evaluation, Tucker's (1975) evaluating model was used. Then, the researchers used the ideas and suggestions of different experienced persons in the field of textbook evaluation both in Iran and abroad -including Brian Tomlinson- and provided a modified version of Tucker's (1975) evaluating model for the study.

Tucker (1975) believes that a system for evaluating textbooks should include basic linguistic, psychological, and pedagogical principles. Accordingly, he discusses four main categories: pronunciation, grammar, content, and general criteria. Each category has some subdivisions.

The rating scheme used with the model is based on three scales:

1. The Value Scale (VS) which shows the relative weight assigned to each one of the mentioned criteria by the evaluator. It consists of a score of 0 to 5 .

2. The Merit Scale (MS) delineates the evaluator's judgment of the text in relation to any specific criterion. It ranges from 0 through 4 numerically. A score of 0 shows that the evaluator considers the text totally lacking any merit in that respect; conversely, a score of 4 reveals the ideality of the book's merit by a specific criterion.

3. The Value Merit Product (VMP), which is a combination of the importance of the criterion and and the merit of the book, can be obtained by the value score times the merit score. 


\subsubsection{Modifications on Tucker's model}

Tucker's model focuses on those elements which are generally considered fundemental to a structural syllabus. However, the researchers want to go a bit further and evaluate the textbooks from the standpoint of communicative language learing and teaching. Thus, Tucker's model is modified to fulfill the objectives of this research.

Since this study focuses on pronunciation, grammar, and content of the mentioned textbooks, the general criteria in Tucker's system are not directly relevant. Thus, they are excluded from the version adapted here.

\section{Analysis \& Discussion}

This part presents the analyses and results of the data collected and their interpretations. As noted earlier, Tucker's (1975) modified model is applied to serve the purpose of the study. The data used in this study was collected through the analysis of $G E$ and $R P E$ series used for the teaching of English in Iranian high schools.

\subsection{Pronunciation}

In this section, the presentation of pronunciation points in GE and $R P E$ series are analyzed. The presentation of pronunciation is evaluated on the basis of three criteria: completeness of presentation, appropriateness of presentation, and adequacy of practices.

\subsubsection{Pronunciation in GE}

\subsubsection{Completeness of presentation}

Fries and Pike (Paulston and Bruder, 1976) classify English consonants as below:

$\mathrm{p}, \mathrm{b}, \mathrm{t}, \mathrm{d}, \mathrm{k}, \mathrm{g}, \mathrm{f}, \mathrm{v}, \theta, \mathrm{\partial}, \mathrm{s}, \mathrm{z}, \mathrm{s}, \mathrm{z}, \mathrm{h}, \breve{c}, \hat{\mathrm{j}}, \mathrm{m}, \mathrm{n}, \mathrm{y}, \mathrm{r}, \mathrm{l}, \mathrm{w}, \mathrm{y}$.

The consonants presented in the GE series consist of the following: t, d, v, $\theta, \partial, \mathrm{s}, \mathrm{z}, \mathrm{y}, \mathrm{w}$.

Considering the consonants of Fries and Pike's system, GE does not present the following consonants: /p/, /b/, /k/, $/ \mathrm{g} /, / \mathrm{f} /, / \breve{\mathrm{s}} /, / \mathrm{z} /, / \mathrm{h} /, / \mathrm{c} /, / \mathrm{j} /, / \mathrm{m} /, / \mathrm{n} /, / \mathrm{r} /, / \mathrm{l} /$, and $/ \mathrm{y} /$.

The following initial clusters are also practiced in GE: st, bl, pl, kl, sk, sl, sp, br, dr, gr, fl. But there are some other initial clusters of two and three consonants that are not presented in GE: fr, gl, pr, tr, $\theta \mathrm{r}$, sw, spr, str.

Vowels

The following vowels are presented and practiced in the GE series: i, i:, u, u:, e, ^ , ə. Considering the Fries-Pike's system, the following vowels are not introduced in GE: æ, o, э. The first two vowels exist in Persian though they are slightly different. The third one does not exist in Persian (Yarmohammadi, 1987); therfore, it should have been presented in a series such as GE.

Considering suprasegmentals; stress is treated from the outset in GE series. The stress of almost all the words which have more than one syllable is displayed though only the primary stress is emphasized. Also, sentence-stress and the stress of some expressions-e.g. Good morning- are practiced in GE. Two main intonation patterns -rising and falling- of English are dealt with in GE series.

On the whole, in GE, pronunciation is largely identified with the articulation of individual sounds and, to a lesser extent, with the stress and intonation patterns of the target language. Consonants, clusters, vowels, stress, and intonation are presented. However, some important points are missing in the presentation of consonants, clusters, and vowels. English syllabic $/ \mathrm{m} /, / \mathrm{n} /, / 1 /$, and $/ \mathrm{r} /$ are of much importance. Also, diphthongs, pitch, and juncture are not presented in GE at all. Therefore, the score of the GE's merit would be 2.

\subsubsection{Appropriateness of presentation}

As far as the linguistic background of Persian students is concerned, the authors of GE try to present the materials on the basis of a contrastive analysis of Persian and English (Manuchehri, 1971). However, as it was discussed earlier, some of the sounds (syllabic $/ \mathrm{m} /, / \mathrm{n} /, / \mathrm{l} /$, and $/ \mathrm{r} /$, etc) which are points of difficulty for Persian students are not dealt with in GE.

Anyhow, the CA of Persian and English sound systems has been the source for the selection and gradation of some of the English sounds in GE. The following segmentals are presented in groups with reference to the above mentioned source:

ii/ and $/ \mathrm{i}: /, / \mathrm{\partial} /$ and $/ \mathrm{d} /, / \theta /$ and $/ \mathrm{t} /, / \mathrm{u}: /$ and $/ \mathrm{u} /$, and $/ \mathrm{w} /$ and $/ \mathrm{v} /$.

A few segmentals are presented in groups because of their voiced/voiceless distinction. For example, / ð/ and $/ \theta /$, and $/ \mathrm{t} /$ and $/ \mathrm{d} /$. 
Considering the inappropriate presentation of some English segmental and also some pronunciation points which are difficult for Persian students, the merit score of GE would be 1.5.

\subsubsection{Adequacy of practice}

Repetition drills represent the only manner in which the sound system of English is practiced in GE. The learners are expected to produce the sounds in words without having the opportunity to discriminate between similar sounds. Moreover, all the consonants and vowels are presented in words, but words - and consequently the sounds - are not practiced in sentences.

Tucker (1975) believes that the quantity of materials for pronunciation practice should be adequate. It is while, /o/, / $\wedge /, / \mathrm{g} /$, and / $\mathrm{u} /$ sounds are not practiced adequately in GE.

Since pronunciation is practiced through just one technique and the segmentals are practiced only in words, and finally since the practice of some sounds is not adequate as far as the CA of English and Persian sound systems is concerned, it would be justified to score GE's merit as 1 as far as the adequacy of practice is concerned.

\subsubsection{Pronunciation in RPE}

\subsubsection{Completeness of presentation}

- Consonants

\section{- Vowels}

The consonants presented in the RPE Book Two series consist of the following:

p, b, t, d, k, g, f, v, $\theta$, d, s, z h, č, m, n, y, r, l, w, y.

As mentioned above, Fries and Pike classify English consonants as below:

p, b, t, d, k, g, f, v, $\theta$, ð, s, z, ̌s, ž, h, č, j, m, n, y, r, l, w, y.

Considering the consonants of this system, Book Two does not present the following consonants: / / ̌s/, / ž/, / $\check{\mathrm{c}} /$, and $/ \hat{\mathrm{j}} /$.

Initial clusters are not practiced in Book Two, though the words which display them are introduced in the book .

bl, pl, sk, sl, sp, br, dr, gr, fl.

\section{Vowels}

The following vowels are presented and practiced in the RPE Book Two :

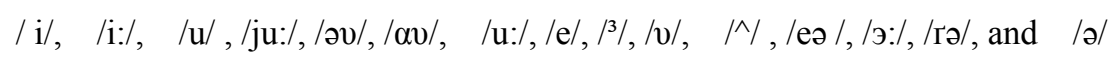

Considering the Fries-Pike's system, the following English vowels are not introduced in the book:

$$
\text { /æ/, and /o/ }
$$

\section{Diphthongs}

The following diphthongs are presented in RPE Book Two: /əv/, / $\alpha v /$, /eə/, and /rə/.

\section{Suprasegmentals}

$\underline{\text { Stress }}$

Stress is not dealt with in RPE Book Two.

\section{$\underline{\text { Intonation }}$}

Intonation is not dealt with in RPE Book Two.

On the whole, in RPE Book Two, pronunciation is largely identified with the articulation of individual and diphthong sounds.

Consonants, and vowels - both individual and diphthong sounds- are points of English pronunciation presented in RPE Book Two. However, some important points are missing, stress, intonation, pitch, and juncture are not presented in the book. Therefore, the score of the RPE's merit would be 2 .

\subsubsection{Appropriateness of presentation}

The authors of RPE try to present the English language sounds, but they miss to present stress, intonation, pitch, and juncture and also some of the sounds like $/ \mathfrak{x} /$, and $/ \mathrm{o} /$. 
Like GE the CA of Persian and English sound systems has been the source for the selection and gradation of some of the English sounds in RPE. The following segmentals are presented in groups with reference to the above mentioned source:

1.

$$
\text { /i/ and /i:/ }
$$

2.

$$
/ \text { ð / and /d/ }
$$

3. $/ \theta /$ and $/ \mathrm{t} /$

A few segmentals are presented in groups because of their voiced/voiceless distinction. For example, / $/$ and $/ \theta /$, and $/ \mathrm{t} /$ and $/ \mathrm{d} /$. Some sounds are presented in groups though they have no specific relationship. For instance, $/ \mathrm{i} /, / \mathrm{g} /$, and $/ \mathrm{st} /$, or $/ \mathrm{w} /, / \mathrm{i} /$, and $/ \mathrm{i}: /$.

Considering the inappropriate presentation of some English segmental and also some pronunciation points which are difficult for Persian students, the merit score of RPE would be 1.5.

\subsubsection{Adequacy of practice}

Like GE, repetition drills represent the only manner in which the sound system of English is practiced in RPE, but here in RPE the learners are expected to produce the sounds both in words and in sentences.

Although pronunciation is practiced through just one technique - repetition drills and the practice of some sounds is not adequate, but the segmentals are practiced both in words and in sentences, so it would be justified to score RPE's merit as 1.5 as far as the adequacy of practice is concerned.

\subsection{Grammar}

\subsubsection{Grammar in GE}

Grammar in GE is analyzed and evaluated on the basis of adequacy of pattern inventory, appropriate sequencing, adequacy of drill model and pattern displays, and finally adequacy of practice.

\subsubsection{Adequacy of pattern inventory.}

In Book Two the concentration is on the simple past along with the distinction between mass and count nouns. Also, comparison - "Ahmad is as old as Mina," "He is taller than ...," "She is more beautiful than ..." - and two auxiliary verbs (must and may) are presented in Book Two.

Although there are some compound nouns in GE, they are not distinguished from nouns as modifiers. Tucker (1975) believes that such a distinction should be included in any beginning text.

The presentation of grammatical patterns in GE is satisfactory enough to score its merit as 3 .

\subsubsection{Appropriate Sequencing}

Although the verb "to be" is irregular, in majority of the available texts it is presented very early because of its very high functional load. GE seems to follow the same order; however, it presents WH questions-e.g. what time is it? before yes/no questions - e.g. are you a student?

Since WH questions involve more transformations than yes/no questions, it would be more appropriate that the latter precedes the former.

The first four lessons of Book Two review the basic structures introduced in Book One. Mass and count nouns and how many / much questions are the structures presented in lessons 5 and 6 . First, mass and count nouns are distinguished; then, how many / much questions are introduced. Although these two successive units show an appropriate sequencing, "how many / much questions" do not appear in the remaining lessons. Of course, "how many /much questions" do appear in some of the drills in Book Two; nevertheless, their appearance is a mechanical review of these structures. In fact, the learner is only reminded of the structures practiced earlier in the book. Possessive forms, simple past tense, comparison, and some modal verbs make up the basic structures sequenced successively in Book Two.

On the whole, GE presents the structures as isolated and loosely related blocks. Sometimes the blocks have no specific relationship and it is not clear why they are arranged in this or that way. As such, the merit score of sequencing in GE would be 2 .

\subsubsection{Adequacy of drill model and pattern displays}

Grammar in GE is to be practiced through oral and written drills. Although the instructions to some of the drills specify the modality, various other drills are not often clearly distinguished. The age and the level of the learners require each drill (or group of drills) to be clearly defined and restricted in terms of the appropriate modality. For 
example, it is not explained how to do drills with titles such as "Change into questions", "Change from 'now' to "every day". Moreover, different instructions are used for the same types of drills, e.g. "Complete the following". "Fill in the missing words", "Fill in the blanks". It would more appropriate to use one instruction for similar kinds of drills as far as the age and level of the learners are concerned. Also, drills of the same modality (e.g. oral) should be grouped together so that the learners could discern easily how they should do the drills.

New patterns are usually written under each other. Vertical lines separate identical grammatical structures (e.g. subjects, verbs) so that the learners could discern the identical structures.

Unfortunately, boxes, arrows, and other graphical devices that could help the learners to understand various patterns are not used in GE.

Because of the above-cited deficiencies in drill model and pattern displays of GE, its merit score would be 2 .

\subsubsection{Adequacy of practice}

Table 1 classifies the drills in GE 2. Moreover, as Table 2 shows, nearly half the drills are of transformation type, in which the learners change some sentences into negative, plural, etc. The drills are numerous, yet since the focus is on transformation type of exercise, they do not represent a variety of drill types.

Insert table 1 here.

Insert table 2 here.

On the other hand, all communicative drills in GE are of reply type in which the learners are to answer some WH-questions. In short, the drills in GE are not distributed adequately to cover various types of drills and to provide appropriate opportunity for practicing the structures.

It seems that the drills in GE are lengthy. There are drills which consist of twenty items. As far as the level of the learners is concerned, drills of this length are tiresome.

On the whole, there is mainly one class and one type of drills in GE- mechanical and transformational, respectively. Therefore, the GE'S merit score would be 1 .

\subsubsection{Grammar in RPE}

Grammar in RPE is analyzed and evaluated on the basis of adequacy of pattern inventory, appropriate sequencing, adequacy of drill model and pattern displays, and finally adequacy of practice.

\subsubsection{Adequacy of pattern inventory.}

Book Two offers two tenses (present continuous and simple past), three modal verbs (can, should, may), and distinguishes between mass and count nouns. It seems that the presentation of adjectives, adverbs, prepositions, and possessives in RPE is sufficient as far as the level of the series is concerned. Yet, it presents a few conjunctions in Book 2. It does not differentiate between nouns as modifiers and compound nouns either. Therefore, it would be fair to score RPE's merit as 3.

\subsubsection{Appropriate Sequencing}

Book Two begins with the present continuous tense only in the statement form. Negative and question forms of this tense are not dealt with, the reason of which is not clear.

The simple past tense of the verb "to be" with its various forms is presented in lessons 3 and 4 . This is a new area which has no relationship with what comes before and after it, because in lessons 5, 6, 7, and 8 adjectives, possessives, mass / count nouns and how much / many questions are introduced. Moreover, all of these structures are constructed in the present tense. After that the past tense of regular and irregular verbs is dealt with and finally three modal verbs are introduced.

The structures are presented in isolated blocks. Some of the units could be switched around without disturbing the order.

In Book Two, there is not a profound sequencing of the grammatical structures. Therefore, the RPE 's merit would be scored as 2 .

3.2.2.3 Adequacy of drill model and pattern displays

There are three kinds of drills in RPE. The titles that display these drills are "Oral drills", "Write it down", and "Speak out". 
Although there are models and examples for most of drills to help the learners discern the exercises, some of the drills are just clarified by explanations written in English. The age and level of the learners require examples and not just explanations.

Basic structures of each lesson are displayed in boxes. The relationships among various patterns and the transformations that any specific structure may involve are illustrated by arrows and small boxes.

From the outset in Book Two, some grammatical terms and explanations are utilized. These are not necessary as far as the level of the learners is concerned. Moreover, the explanations may impel the learners to concentrate more on the grammarian's jargon than on aspects essential for language learning.

Some of the drills are accompanied by pictures. And about ten type faces in black and red are used in RPE.

On the whole, drill models and pattern displays are adequate in RPE and hence its merit score would be 3.

\subsubsection{Adequacy of practice}

As tabulated in Table 3, mechanical drills form the majority of the drills in RPE. In fact, Book 2 does not provide enough chance for the learners to practice the structures communicatively. Mechanical drills are presented more than meaningful and communicative drills.

Table 4 shows that there are two main types of drills in RPE, completion and single slot substitution. These drills constitute more than half of all the drills in Book 2. Seven types of drills are repeated less than six times in the book. Although the drills in RPE are more divers than in GE, they are far from being exhaustive.

The length of the drills in RPE seems to accord with the age and the level of the learners. There are only 22 (out of 288) drills which consist of 9 to 12 items. The majority of the drills consist of five items.

Insert table 3 here.

Insert table 4 here.

In summary, there are mainly one class- mechanical- and two types- completion and single slot substitution- of drills in $R P E$. The length of the drills seems appropriate. Nevertheless, $R P E$ does not present an adequate number of meaningful and communicative drills. Therefore, its merit score would be2.

\subsection{Content}

\subsubsection{Content in GE}

This section aims at evaluating the content of GE on the basis of functional load, rate and manner of entry and re-entry, and the appropriateness of contexts and situations.

\subsubsection{Functional load}

Book Two presents expressions such as "I am happy to have you.", "what grade are you in?", "of course", and some other expressions. Of course, these expressions are presented only once and rarely twice throughout the book. The expressions used in naming the months are presented nearly at the end of book two. It is while; expressions for naming the days, months, etc. must be and could be used much earlier. In other word, GE does not benefit from the structures and expressions appropriately as far as functional load is concerned. Accordingly, its merit score would be 1.

\subsubsection{Rate and manner of entry and re-entry}

Book Two do not present a quite balanced rate of entry of vocabulary. For example, unit 13 presents 27 new words, while unit 16 introduces only 8 new words. These two units present the most and least number of new words in the second book. As far as the re-entry of grammatical structure is concerned, "how many/much" questions introduced in unit 6 are not re-presented throughout the units succeeding this unit. And "comparison" which is offered in units 15 and 16 is not re-used in the succeeding units, too.

Moreover, some words and grammatical structures do not play active roles in various units though they are introduced in GE. Accordingly, the GE's merit score would be 1.5 as far as rate and manner of entry and re-entry are concerned.

\subsubsection{Appropriateness of contexts and situations}

GE presents a lot of its vocabularies and grammatical structures in isolated sentences. Obviously, isolated sentences could not present appropriate contexts and situations because; it is possible to attribute different meanings to an isolated sentence. 
Regarding the appropriateness of contexts and situations there is a dialogue in Unit One which is accompanied by a picture of a classroom. There are some students and a teacher in the classroom. Both the teacher and the students are males. In the dialogue the teacher says "we all speak English in the classroom". Such an utterance is not appropriate as far as the context of this dialogue is concerned. Since all of them (the teacher and the students) have already spoken English, there is no need to say such a sentence. Moreover, there is no relationship between this sentence and other sentences. In other words, this sentence breaks down with the propositional development of the dialogue. As such, it disturbs the coherence of the dialogue.

On the whole, GE dose not provide appropriate contexts and situations in its dialogues. In almost all of the GE conversations, little attention is paid to those functions which often dominate in face-to-face interaction. Of course, there are a few exceptions; nevertheless, majority of dialogues in GE suffer from not being cohesive and coherent. Also in nearly all of these dialogues the emphasis is often on usage rather than use. Considering all of the above serious deficiencies, GE lacks any merit as far as the appropriateness of contexts and situations is concerned and its score would be 0 .

\subsubsection{Content in RPE}

This section aims at evaluating the content of RPE on the basis of functional load, rate and manner of entry and re-entry, and the appropriateness of contexts and situations

\subsubsection{Functional load}

Various expressions of greeting, leave-taking, and courtesy are introduced throughout Book Two. They are: "Hello", "How are you?", "Fine, thank you", "Not too bad", "Nice to see you", "See you tomorrow", "That's too bad", and "Thank you".

These expressions are presented as formulas and their structures are not analyzed for the learners. They are presented in dialogue of each unit; they are often repeated near the end of that unit with some of its words replaced by blanks to be filled in by the learners. These mechanical "fill in the blanks" drills form the only type of exercise for practicing the above-mentioned expression.

The simple present tense of "to be "and "to have" are presented before irregular verbs because of their functional load. Both of these verbs are also re-presented throughout RPE.

In brief, RPE presents some words, expressions, and structures with respect to their functional load. However, RPE overemphasizes greeting and does not provide appropriate opportunities for the learners to practice the introduced functions. Therefore, RPE's merit would be scored as 2.5 .

\subsubsection{Rate and manner of entry and re-entry}

The rate of introducing new words in the units of RPE 2 ranges from 10 to 25 . Some units introduce only one new grammatical structure. Tucker (1975) suggests that in early units, vocabulary should be introduced sparingly.

One to three grammatical structures are presented in each unit of RPE. Such a rate of entry of grammatical structures seems to be adequate. Nevertheless, the re-presentation of some of them is not adequate. For instance, the present continuous tense is presented in lesson two of book two, but it is not re-presented throughout the book. Also, the simple past tense of the verb "to be", which is introduced in units 3 and 4, does not play any role in the four succeeding lessons. In this respect, Tucker (1975) remarks that if a verb tense is introduced, it should play a substantial part in the majority of the units. In RPE the presentation of the mentioned grammatical structures does not follow such a manner.

RPE, on the whole, introduces the structure properly, but the introduction of vocabulary and expressions has some inadequacies. On the other hand, the re-entry of structures is not appropriately handled. Therefore, its merit score would be 2.5

\subsubsection{Appropriateness of contexts and situations}

RPE offers a systematic presentation of dialogues. With the exception of the first unit, each of the units of Book Two consists of a dialogue which is accompanied by pictures.

Dialogues 2, 3, 4, 5, 6, 7, 8, 9, 11, and 12 of Book Two, totally or partially, display the English language usage. If a question is asked in these dialogues, it is not for the manipulation of language in communication, but for exhibiting a grammatical point.

In addition, some of the dialogues in RPE have special inadequacies, for example, in the second dialogue of Book Two, Reza calls Ali, but this is Ali who asks all the questions. Generally speaking, one expects to know why Reza 
calls Ali. On the contrary, not only does Ali ask all of the questions, but also he finishes up the conversation and wants Reza to call him later.

In summary, the dialogues in RPE basically deal with English usage. Even in this respect, some of the utterances are not appropriate. It needs to be pointed out that English usage could be handled directly in drills, and dialogues should be left for the presentation of natural English utterances. Therefore, the emphasis which is put on usage in RPE's dialogues is not appropriate. On this basis, RPE's merit would be scored as 0.5 .

\section{Conclusion}

In this study, GE and RPE were compared and contrasted. The advantages and disadvantages of each series were evaluated for pronunciation, grammar, and content on the basis of Tucker's (1975) evaluation system.

Based on the analysis of the two series, there are not considerable differences between GE and RPE. The major difference lies in the pronunciation criteria in which GE has several serious inadequacies which should have obviously been amended in RPE. However, RPE does not accomplish completely the GE's deficiencies in the domain of pronunciation.

GE and RPE are best esteemed on the grammar criteria. This reveals, on the one hand, the fact that they are fundamentally based on the structural views of syllabus design, on the other, that RPE does not correct completely the inadequacies of GE as far as the fundamental concepts of syllabus design are concerned. In other word, RPE does not operate beyond the structural syllabus, and its superiority over GE is quantitative rather then qualitative. That is, RPE presents the structural syllabus better than GE. It presents and practices better structural exercises. If we consider the seventh criterion (adequacy of practice) in which communicative aspects of drills, on the basis of Paulston and Bruder (1976) classification of grammar exercises are also taken into consideration, RPE and GE gain the least merit in the area of grammar. In other words, RPE does not present and practice the English grammar as far as communicative competence is concerned.

The shortcomings of GE and RPE to accord with the communicative aspects of language teaching - or specifically syllabus design and text construction - are much more revealed in applying the content criteria and specially the tenth criterion which inspects the appropriateness of contexts and situations. In this respect, GE lacks any merit and RPE gains only marginally.

As it was remarked earlier, the authors of RPE claimed that they had tried to incorporate the recent improvement in language teaching and learning in designing RPE. The results of this study show that RPE did employ the recent improvement in some areas not in all the areas. RPE achieves better scores in the grammar and the content criteria.

All in all, the results of this study reveal that RPE does not correct most of the inadequacies and deficiencies of GE. Moreover, it fails to incorporate the recent findings in syllabus design and text construction. In other words, the development of RPE is not, by and large, a step forward towards constructing an up-to-date series for the teaching of English in Iranian schools.

On the whole, the two textbook series are found to have overemphasized the practice of the linguistic forms, and not many of their language learning activities actually include activities which stimulate or lead to authentic communication and language use.

To sum up, these textbooks can not meet the learners' and the teachers' needs within the Iranian educational system and it is a bit strange that they still emphasize structural methods and ignore the communicative role of the language.

\section{Referenes}

Amalsaleh, E. (2004). The representation of social factors in the EFL textbooks in Iran. Unpublished doctoral dissertation, Shiraz University, Shiraz.

Ansary, H., \& Babaii, E. (2002). Universal characteristics of EFL/ESL textbook: A step towards systematic textbook evaluation. The Internet TESL Journal, 2, 1-8.

Birjandi, P., Nowrozi, M., and Mahmodi, G.H. (2002). Right Path to English. Tehran: The Center for Printing and Publishing of Textbooks.

Hutchinson, T. \& Torres, E. (1994). The textbook as agent of change. ELT Journal, 48(4), 315-328.

Iran. Ministry of Education. (1984). Graded English. 7 vols. Tehran: Sherkat Chap va Nashr Iran.

Leach, G. \& J. Svartvik. (1975). A Communicative Grammar of English. London: Longman.

Manuchehri, P. (1971). 'Towards a New School Course: The Graded English Series' in J. Stevenson 1971: 26-35.

McGrath, I. (2002). Materials Evaluation and Design for Language Teaching. Edinburgh: Edinburgh University Press. 
Paulston, C. B. and M. N. Bruder. (1976). Teaching English as a Second Language: Techniques and Procedures. Boston: Little, Brown and Company.

Tomlinson, B . (2001). Materials development. In R. Carter and D. Nunan (Ed.), The Cambridge Guide to Teaching English to Speakers of Other Languages. Cambridge: Cambridge University Press.

Tucker, C. A. (1975). Evaluating beginning textbooks. English Teaching Forum. 13: 355-61.

Yarmohammadi, L. (1987). Contrastive Analysis of English and Persian Sounds. Mimeograph.

Yarmohammadi, L (2002). The evaluation of pre-university textbooks. The Newsletter of the Iranian Academy of Science, 18, 70-87.

Table 1. Classification of drills in GE 2

\begin{tabular}{|l|l|l|l|c|}
\hline \multirow{2}{*}{ GE: Book2 } & Mechanical drills & Meaningful drills & Communicative drills & Total 1 \\
\cline { 2 - 5 } & 93 & 1 & 9 & 103 \\
\hline
\end{tabular}

Table 2. Range of various types of drills in GE 2

\begin{tabular}{|c|c|c|c|c|c|c|c|c|c|c|c|c|c|c|}
\hline \multirow{2}{*}{$\begin{array}{l}\text { Types of } \\
\text { drills }\end{array}$} & \multicolumn{10}{|c|}{ Mechanical } & \multicolumn{3}{|c|}{ MEANINGFUL } & \multirow{2}{*}{ 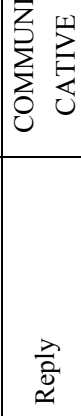 } \\
\hline & 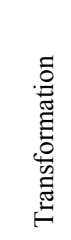 & 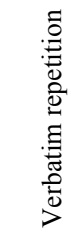 & 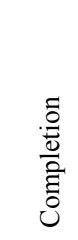 & 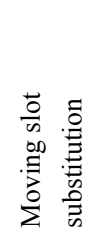 & 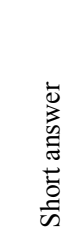 & 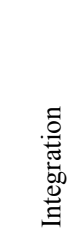 & 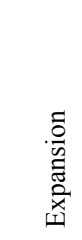 & 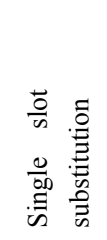 & 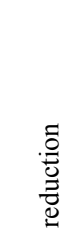 & 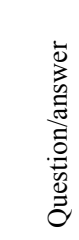 & & 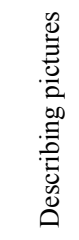 & $\begin{array}{l}\frac{\lambda}{2} \\
\stackrel{2}{\simeq}\end{array}$ & \\
\hline 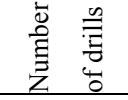 & 41 & 20 & 11 & 11 & 2 & 4 & 2 & 1 & 1 & 0 & 0 & 1 & 0 & 9 \\
\hline
\end{tabular}

Table 3. Classification of drills in RPE 2

\begin{tabular}{|l|l|c|c|c|}
\hline \multirow{2}{*}{$\begin{array}{l}\text { RPE: } \\
\text { Book2 }\end{array}$} & Mechanical drills & Meaningful drills & Communicative drills & Total 1 \\
\cline { 2 - 5 } & 110 & 16 & 3 & 129 \\
\hline
\end{tabular}

Table 4. Range of various types of drills in RPE 2

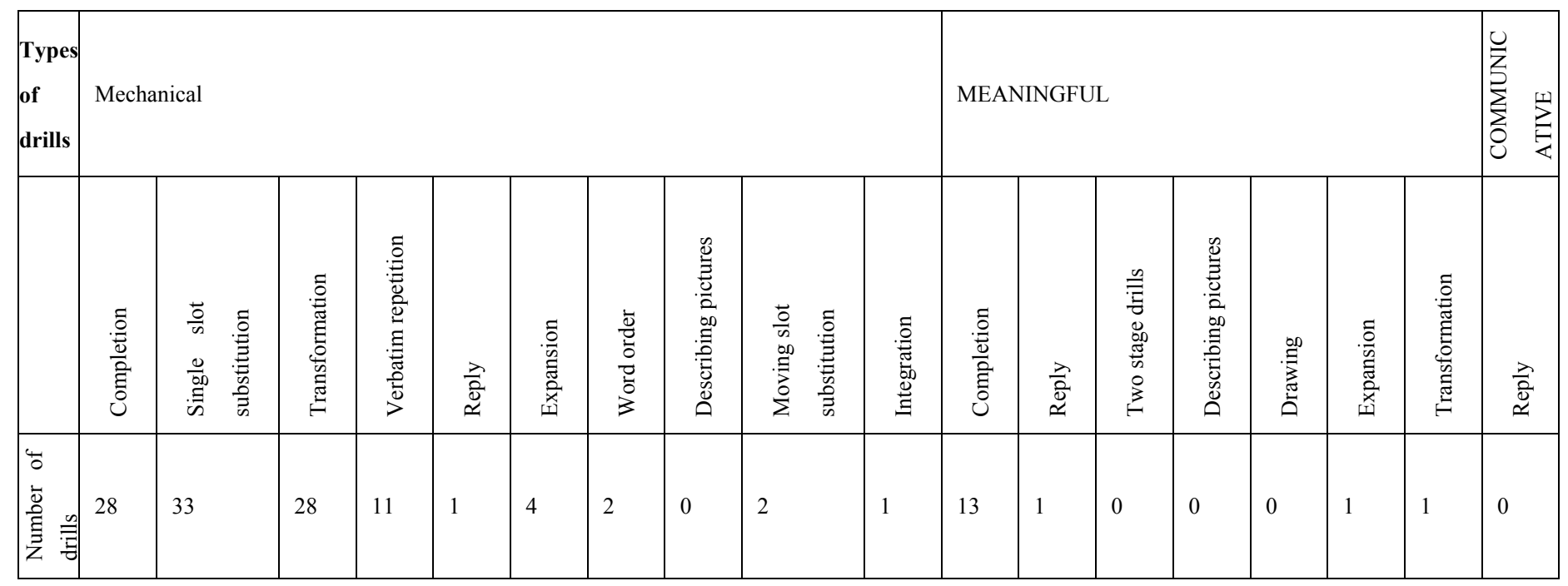

